\title{
MERANCANG BANGUN WEB E-COMMERCE MENGGUNAKAN WORDPRESS STUDI KASUS TOKO ARLEUIS
}

\author{
Muhammad Nur Ibnu Wicaksono ${ }^{1}$, Hendri Irawan ${ }^{2}$ \\ ${ }^{1,2}$ Fakultas Teknologi Informasi, Sistem Informasi, Universitas Budi Luhur, Jakarta, Indonesia \\ Email:*1nuribnu1590@gmail.com, ${ }^{2}$ hendri.irawan@budiluhur.ac.id
}

\begin{abstract}
Abstrak - Toko Arleuis adalah sebuah unit usaha kecil menengah yang menjual berbagai macam pakaian berlokasi di Kembangan, Jakarta Barat. Saat ini, proses bisnis transaksi penjualannya dilakukan secara langsung, yakni pelanggan berkunjung ke toko serta dapat juga bertransaksi melalui media sosial. Seiring berkembangnya waktu pemilik toko ingin meningkatkan penjualannya tapi terbatas pada media yang bisa dimanfaatkan untuk mempromosikan pakaian dan melayani para pembelinya. Media sosial yang saat ini dimanfaatkan untuk mempromosikan pakaian sekaligus melayani para pembeli yang memesan secara online, kurang efektif karena sering terjadinya penumpukan chat dari para pembeli yang hanya ingin bertanya mengenai produk ataupun para pembeli yang mengirimkan bukti pembayarannya kepada pemilik, sehingga pemilik toko sering kesulitan untuk memprioritaskan chat mana yang harus dibalas dan juga kesulitan dalam mencari bukti pembayaran dari para pembelinya. Untuk menyelesaikan permasalahan tersebut maka dibuatkan sistem E-commerce menggunakan Content Management System (CMS) Wordpress sebagai usaha memberikan pemecahan atas permasalahan yang ada, dan Business Model Canvas guna memvisualisasikan proses bisnis pada Toko Arleuis agar bisa menghasilkan kinerja yang lebih maksimal. Hasil penelitian ini yaitu merancang bangun website E-commerce yang memberikan kemudahan kepada para pelanggannya pada saat bertransaksi, dan membantu pemilik dalam pemasaran dan meningkatkan penjualan serta luaran informasi yang lebih baik.
\end{abstract}

Kata Kunci: penjualan online, ecommerce, content management system, cms wordpress

\begin{abstract}
Toko Arleuis is a small and medium business unit that sells various kinds of clothing located in Kembangan, West Jakarta. Currently, the sales transaction business process is carried out directly, namely customers visit the store and can also transact through social media. Over time, shop owners want to increase their sales but are limited to media that can be used to promote clothes and serve their buyers. Social media, which is currently being used to promote clothing and at the same time serve buyers who order online, is less effective because there is often a buildup of chat from buyers who just want to ask questions about products or buyers who send proof of payment to the owner, so shop owners often find it difficult to prioritize which chats to reply to and also difficulty in finding proof of payment from buyers. To solve these problems, an E-commerce system was created using the Content Management System (CMS) WordPress as an effort to provide solutions to existing problems, and a Business Model Canvas to visualize business processes at the Arleuis Store in order to produce maximum performance. The results of this study are designing an E-commerce website that provides convenience to its customers when transacting, and assisting owners in marketing and increasing sales and better information output.
\end{abstract}

Keywords: online sales, ecommerce, content management system, cms wordpress

\section{PENDAhUluan}

Kebutuhan informasi yang cepat dan akurat menuntut para pemberi informasi untuk dapat memanfaatkan teknologi internet sebagai media penyampaiannya. Teknologi internet yang berkembang saat ini tidak hanya dimanfaatkan sebagai media untuk saling bertukar informasi tetapi digunakan juga untuk melakukan kegiatan berbisnis secara online, pemanfaatan internet sebagai media untuk melakukan kegiatan berbisnis secara online ini biasa dikenal dengan E-commerce. Merupakan sistem perdagangan online, dimana pelanggan hanya mengunjungi situs $w e b$ yang dibuat penjual untuk melihat produk apa saja yang sedang dijual, dan melakukan pemesanan secara online [1].

Salah satu usaha yang ingin menerapkan E-commerce sebagai sistem untuk menunjang usahanya adalah toko pakaian Arleuis yang berlokasi di pasar malam CNI Kembangan, Jakarta Barat. Arleuis merupakan toko yang bergerak di bidang penjualan berbagai macam pakaian baik untuk pria maupun wanita. Arleuis memiliki masalah dalam hal untuk menunjang proses transaksi penjualan pakaiannya, apalagi dimasa Pandemi Covid - 19 yang membuat pemerintah membuat aturan tentang Pemberlakuan Pembatasan Kegiatan Masyarakat (PPKM) mewajibkan masyarakat berada di rumah saja demi menekan laju penyebaran pandemi ini semakin membuat Arleuis mengalami penurunan dalam hal penjualan pakaiannya, saat ini Arleuis belum mempunyai website sebagai sarana promosi dan penjualan produknya. Media sosial Instagram yang digunakan oleh pemilik toko untuk mempromosikan produknya kepada para followers dan calon pembeli Arleuis, begitupun Whatsapp yang hanya dimanfaatkan oleh pemilik toko untuk mempromosikan produknya kepada kerabat atau teman dekat sipemilik toko melalui fitur story Whatsapp. 
Dari beberapa media yang sudah dimanfaatkan oleh pemilik Toko Arleuis, seringkali si pemilik toko mengalami kesulitan saat melakukan pengecekan bukti transfer dan juga banyaknya chat yang masuk sering membuat si pemilik toko kesulitan mencari chat dari sang calon pembeli, selain itu pemasaran produk yang kurang luas juga membuat produk Arleuis kurang dikenal oleh banyak orang. Oleh karna itu sipemilik toko membutuhkan sebuah sistem dengan konsep ecommerce untuk menangani beberapa permasalahan dalam hal penjualan online tersebut.

Penelitian ini memiliki tujuan untuk dapat meningkatkan penjualan produk pakaian pada Toko Arleuis dengan pemanfaatan penggunaan E-commerce sebagai media yang akan meningkatkan kemudahan berbelanja, memfasilitasi para pembeli, reseller dan memudahkan pelayanan pemesanan secara online bagi pemilik Toko Arleuis. Beberapa studi literatur yang dipakai dalam penelitian ini yaitu: penelitian [2] yang membahas berkenaan sistem informasi penjualan untuk mengoptimalkan penjualan batik dengan E-commerce. Penelitian kedua [3] membahas pembuatan website berbasis E-commerce menggunakan CMS dan metode BMC guna memperluas pemasaran. Penelitian ketiga [4] membahas mengenai perancangan E-commerce untuk meningkatkan penjualan menggunakan pemrograman PHP dan database MySql. Berdasarkan analisis sistem berjalan pada Toko Arleuis serta studi literatur yang ada maka peneliti merancang bangun website E-commerce sesuai dengan kebutuhan Toko Arleuis. Adapun rumusan masalah dari Toko Arleuis yang harus dijawab adalah bagaimana membuat model E-commerce dan strategi penjualan pakaian yang dapat membantu Toko Arleuis menyelesaikan permasalahannya.

\section{METODOLOGI PENELITIAN}

Penelitian yang baik haruslah berjalan secara sistematis, memiliki alur penelitian yang dilakukan dengan menetapkan metode dan tahapan yang digunakan untuk memecahkan masalah penelitian yang sedang diteliti [4]. Urutan alur penelitian dalam aktivitas analisis dan melakukan perancangan pada Toko Arleuis merujuk pada Gambar 1. Metode Penelitian.

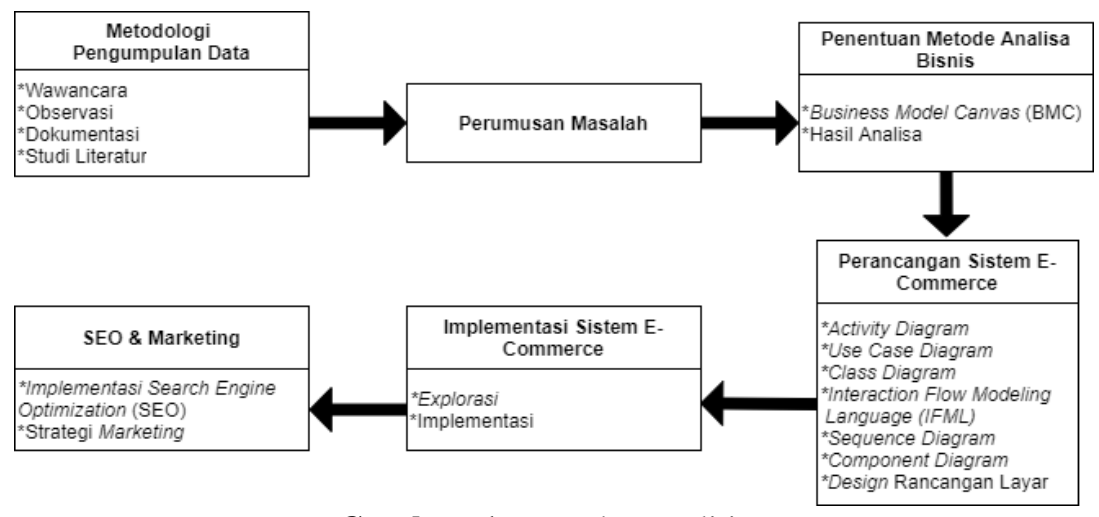

Gambar 1. Metode Penelitian

Berdasarkan Gambar 1 metodologi penelitian yang digunakan oleh penulis dalam melakukan penelitian di Toko Pakaian Arleuis diawali dengan melakukan pengumpulan data yang meliputi proses wawancara, observasi, dokumentasi dan studi literatur terkait topik penelitian yang diangkat oleh penulis, setelah dilakukan pengumpulan data maka penulis mendapatkan kesimpulan dari hasil.

\section{HASIL DAN PEMBAHASAN}

\subsection{Business Model Canvas}

Bussines Model Canvas adalah sebuah metode yang dipakai untuk menggambarkan serta menganalisis, merancang model bisnis suatu perusahaan [5]. Ada 9 bagian yang dimiliki oleh business model canvas yaitu Value Proposition, Key Partners, Key Activities, Customer Segments, Key Resource, Customer Relationship, Channels, Cost Structure, Revenue Stream. Business Model Canvas pada Toko Arleuis dapat dilihat pada Gambar 2. Business Model Canvas Arleuis. 


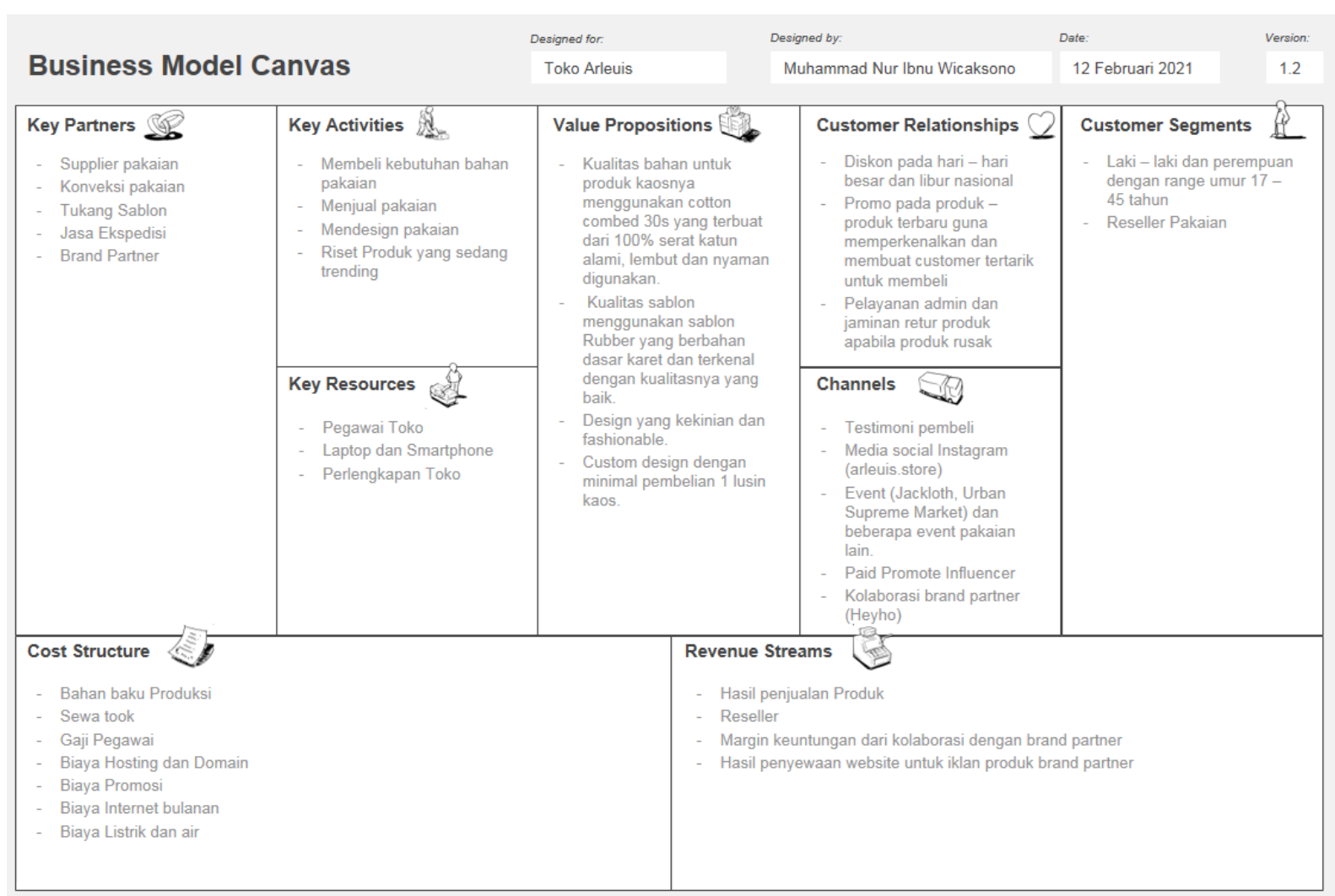

Gambar 2. Business Model Canvas Arleuis

Kanal business model canvas yang terdapat pada Toko Arleuis beserta deskripsinya yang telah di analisis adalah sebagai berikut :

a. Value Propotition sebuah nilai yang ditawarkan oleh Toko Arleuis terhadap produknya kepada para pelanggannya yaitu kualitas bahan pada produk kaosnya, kualitas sablon dan design yang diklaim kekinian dan mengikuti perkembangan zaman.

b. Customer Segment adalah target pelanggan yang menjadi fokus utama penjualan produk Toko Arleuis adalah pria dan wanita dengan range berusia 17 - 45 tahun menurut pemilik toko range umur 17 - 45 tahun merupakan pengunjung toko yang paling sering datang untuk sekedar melihat atau membeli produk Toko Arleuis.

c. Channel adalah cara Toko Arleuis dalam menjangkau customer dengan memberikan informasi seputar produk mereka melalui media sosial dan event pakaian yang sering digelar oleh komunitas atau masyarakat, tak jarang para pembeli memberikan testimoni produk yang kemudian mereka bagikan diakun sosial media mereka sehingga semakin memungkinkan untuk lebih dikenalnya lagi produk dari Toko Arleuis.

d. Customer Relatonships adalah strategi yang digunakan oleh pemilik Toko Arleuis untuk menjalin relasi dengan pelanggan yaitu dengan diskon dan promo pada produk - produk terbarunya.

e. Revenue Stream adalah sumber pendapatan yang didapat pada Toko Arleuis yaitu dari hasil penjualan produk pakaiannya.

f. Key Activities adalah kegiatan yang dilakukan di Toko Arleuis antara lain membeli kebutuhan bahan pakaian, menjual dan mendesign pakaian juga melakukan riset produk kekinian dan yang sedang trend dipasaran.

g. Key Resource adalah sumber daya yang terdapat pada Toko Arleuis seperti pegawai, laptop, smartphone dan perlengkapan toko sangat dijaga untuk mendukung kemajuan dari Toko Arleuis.

h. Key Partners adalah mitra yang berkerja sama dengan Toko Arleuis yaitu, supplier bahan pakaian, konveksi, tukang sablon dan juga jasa ekspedisi.

i. $\quad$ Cost Structure adalah biaya yang harus dialokasikan untuk keperluan Toko Arleuis. 
available online at $\mathrm{http}: / /$ jom.fti.budiluhur.ac.id/index.php/IDEALIS/index

\subsection{Proses Bisnis Usulan}

Pada langkah merancang analisis kegiatan proses bisnis usulan penulis membuat rancangan aktivitas kegiatannya menggunakan Activity diagram guna mempermudah dalam hal pembacaan kegiatan pada proses bisnis usulan yang penulis usulkan. Diagram ini menggambarkan alur aktivitas yang merepresentasikan berbagai jenis aktivitas pengguna atau sistem [6]. Beberapa Activity Diagram proses bisnis usulan pada website Toko Arleuis yaitu :

\section{a. Activity Diagram proses pemesanan produk}

Pada proses pemesanan produk, diagram ini menjelaskan interaksi pembeli dengan sistem Toko Arleuis. Pembeli masuk ke website Toko Arleuis, pembeli melihat - lihat produk yang ada di website Toko Arleuis, lalu pembeli memilih produk yang diinginkan, setelah itu pembeli akan memasukkan berapa jumlah barang yang akan ia pesan dan ukuran dari produk yang ia pesan lalu pembeli menekan tombol Tambah ke keranjang, kemudian sistem secara otomatis menjumlahkan total harga sementara pada barang yang akan dibeli tadi. Selanjutnya pembeli pilih menu keranjang yang ada di menu website, pada halaman ini pembeli dapat melihat daftar barang yang dipilih, pembeli juga dapat merubah isi jumlah barang yang dipesan. Selanjutnya pembeli melakukan proses checkout dengan cara mengklik tombol Lanjutkan ke Checkout. Lalu pembeli diminta untuk mengisi form pemesanan barang berupa nama, alamat email dan nomor handphone. Setelah itu pembeli mengklik tombol Buat pesanan dan sistem akan memproses pesanan si pembeli. Lalu pembeli tadi akan diarahkan menuju halaman yang berisi tentang informasi detail pesanan dan akun bank Toko Arleuis untuk selanjutnya pembeli melakukan proses pembayaran. Activity Diagram pemesanan produk tertuang pada Gambar 3. Activity Diagram proses pemesanan produk.

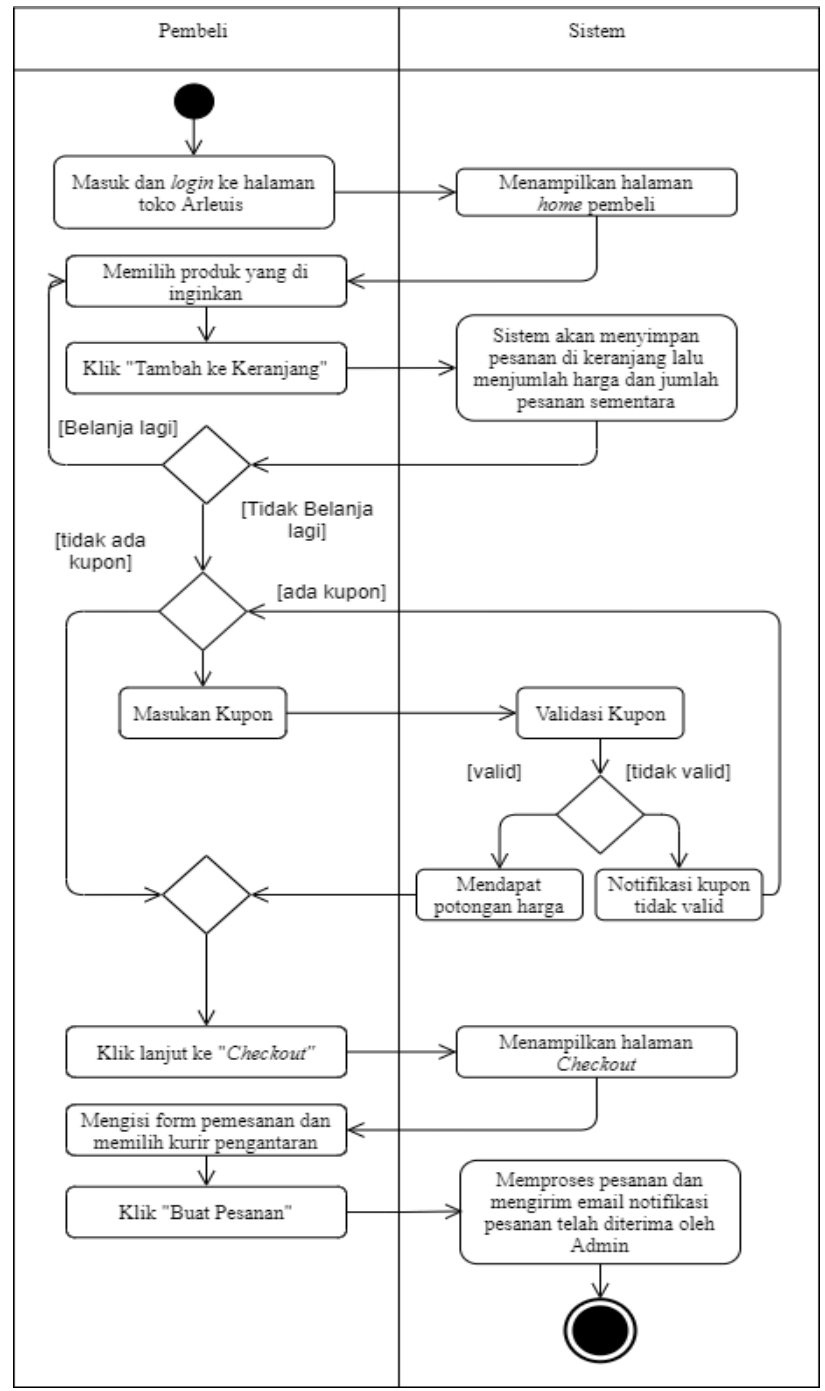

Gambar 3. Activity Diagram proses pemesanan produk 


\section{b. Activity Diagram Proses Pembayaran}

Activity Diagram Proses Pembayaran menjelaskan alur pembayaran pada website Toko Arleuis. Pembeli dapat melakukan proses pembayaran melalui transfer uang ke rekening bank Toko Arleuis sesuai dengan total pembayaran yang terdapat dirincian pembelian produk. Setelah pembeli menyelesaikan pembayaran pembeli dapat melanjutkan proses untuk mengkonfirmasi pembayaran yakni dengan cara memilih menu konfirmasi pembayaran dan mengisi form konfirmasi pembayaran dengan melampir kan beberapa data yang diminta oleh sistem. Lalu pembeli mengklik tombol konfirmasi. Setelah itu sistem akan memproses konfirmasi pembayaran si pembeli, lalu admin akan menerima email konfirmasi pembayaran yang telah dikirim oleh si pembeli dan akan melakukan validasi data konfirmasi pembayaran yang dilakukan oleh pembeli tadi, jika valid maka admin akan memproses pesanan dan merubah status pemesanan si pembeli, namum jika data yang dikirimkan tidak valid maka admin tidak akan memproses pesanan tersebut. Seperti terlihat pada Gambar 4. Activity Diagram Proses Pembayaran.

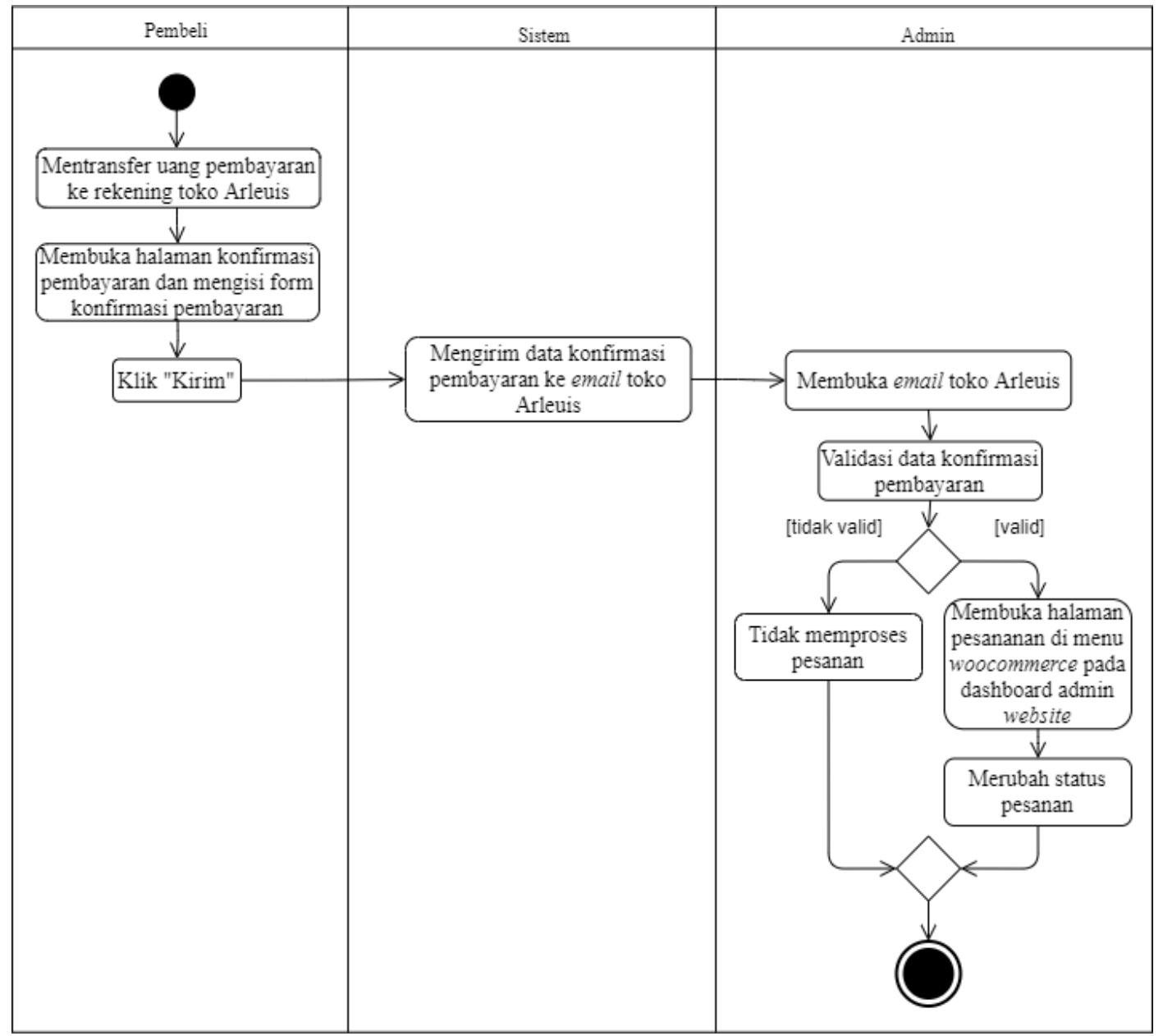

Gambar 4. Activity Diagram Proses Pembayaran

\subsection{Use Case Diagram}

Use Case Diagram adalah urutan atau deskripsi aktivitas yang membentuk sistem yang saling berhubungan yang dijalankan atau dipantau secara teratur oleh seorang aktor [7]. Penulis membuat use case diagram yang disesuaikan dengan sistem usulan yang akan dibuat pada website Toko Arleuis. Use Case Diagram pada Toko Arleuis diantaranya ada Use Case diagram master, transaksi dan laporan. Selain itu Use case Diagram ini berisi beberapa aktor yaitu, admin, pemilik, pembeli dan sistem yang saling berinteraksi yaitu pada Gambar 5. Use Case Diagram Toko Arleuis. 

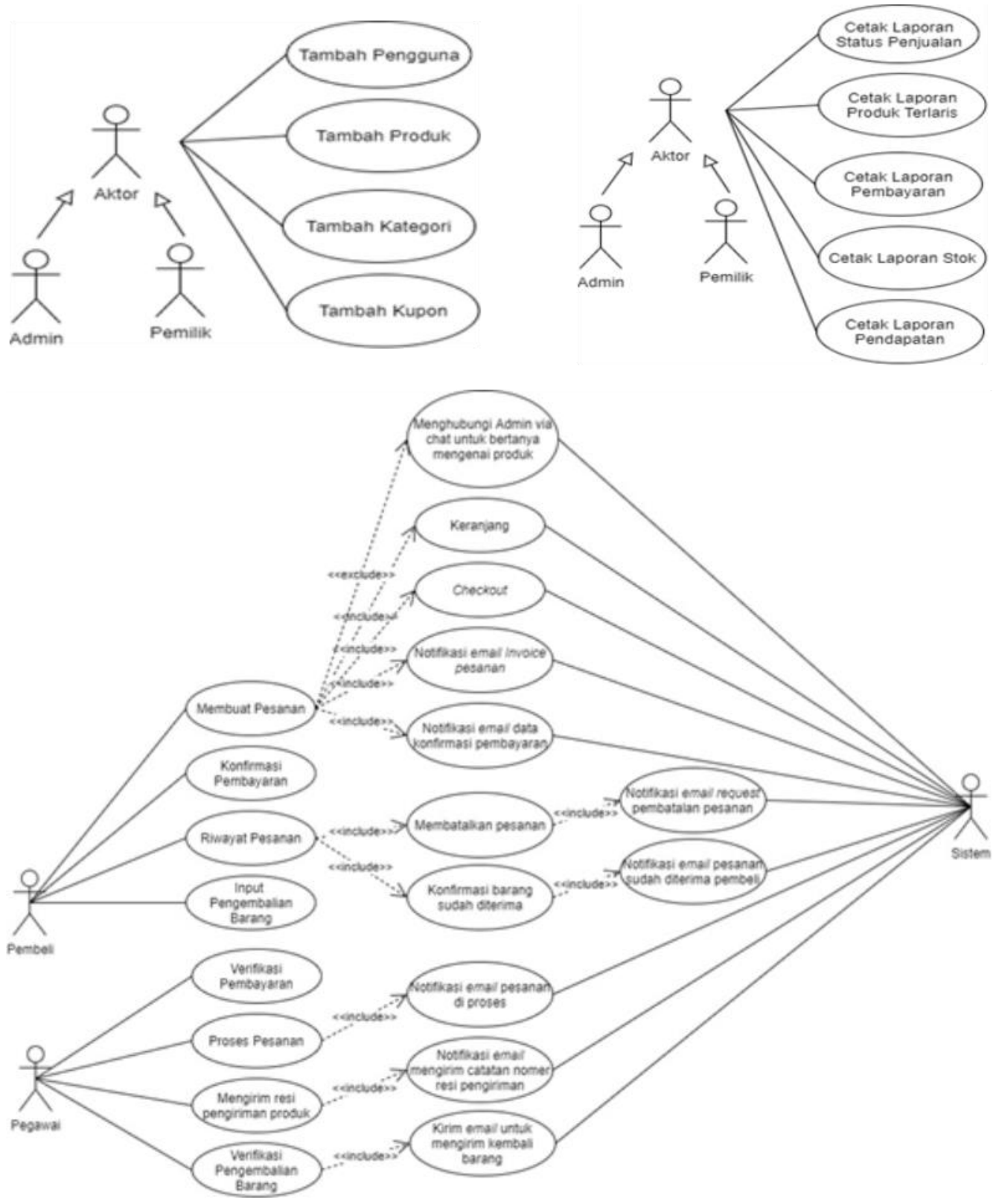

Gambar 5. Use Case Diagram Toko Arleuis

\subsection{Rancangan Layar}

Rancangan layar merupakan prototipe tampilan awal situs web berfungsi sebagai antarmuka pengguna untuk sistem atau aplikasi [8]. Rancangan layar harus digambarkan dengan baik agar user mudah memahami kegunaan setiap menu yang ada pada sistem (user friendly).

a. Rancangan Layar Beranda

Rancangan layar Beranda ini berfungsi sebagai halaman beranda pembeli pada website Toko Arleuis. Tampilan ini juga merupakan tampilan awal website ketika pembeli mengunjungi halaman website Toko Arleuis yang beralamatkan di arleuis.com. Tampilan halaman ini seperti terlihat pada Gambar 6. Rancangan Layar Beranda. 
INDONESIA JOURNAL INFORMATION SYSTEM (IDEALIS)

Volume 5, Nomor 1, Januari 2022

ISSN 2684-7280 (online)

Halaman 9-18

available online at http://jom.fti.budiluhur.ac.id/index.php/IDEALIS/index

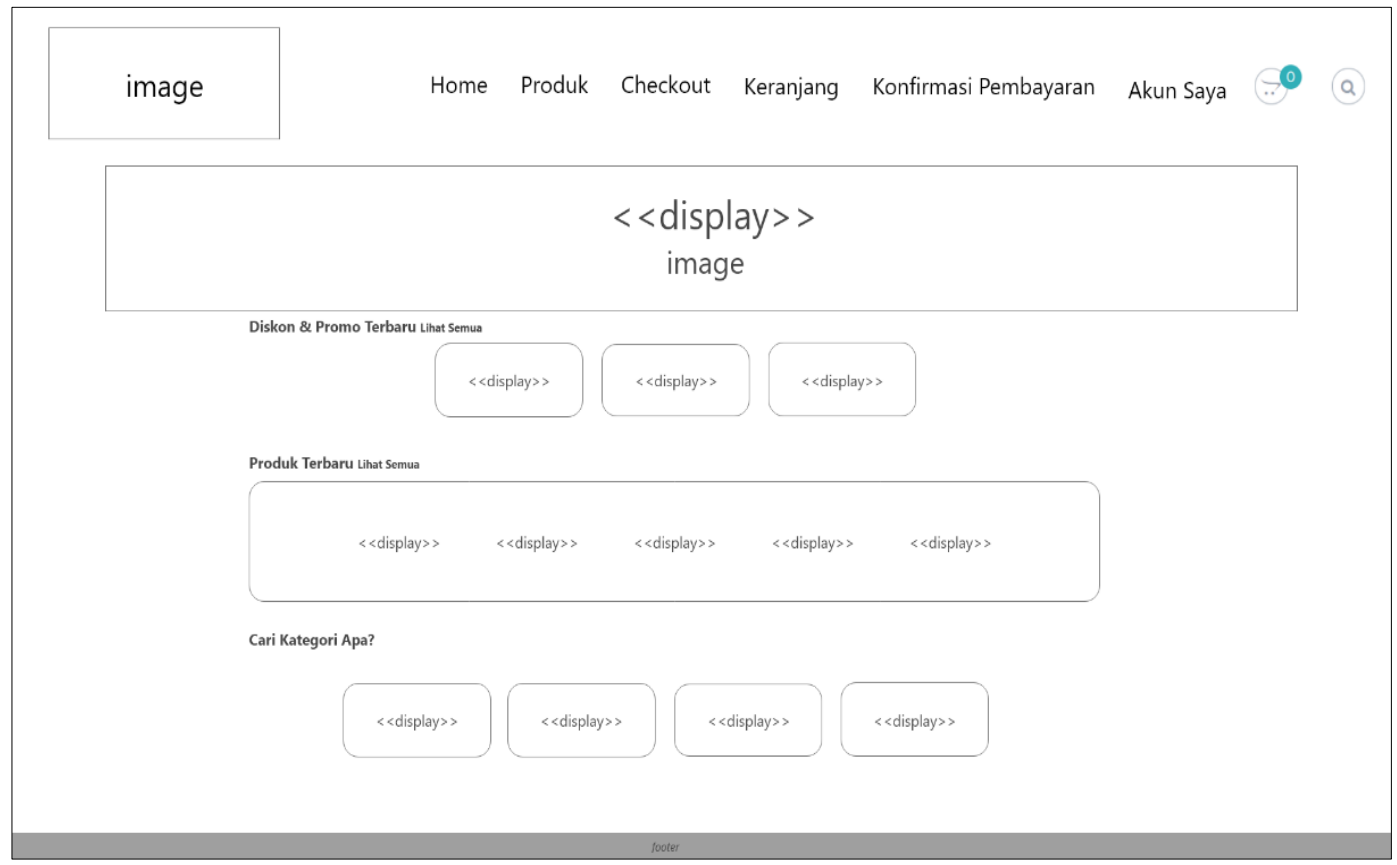

Gambar 6. Rancangan Layar Beranda

b. Rancangan Layar Checkout

Rancangan layar Checkout ini berfungsi sebagai halaman pembeli untuk melanjutkan pesanan ke checkout dan melakukan pembayaran pesanan, halaman ini seperti terlihat pada Gambar 7. Rancangan Layar Checkout.

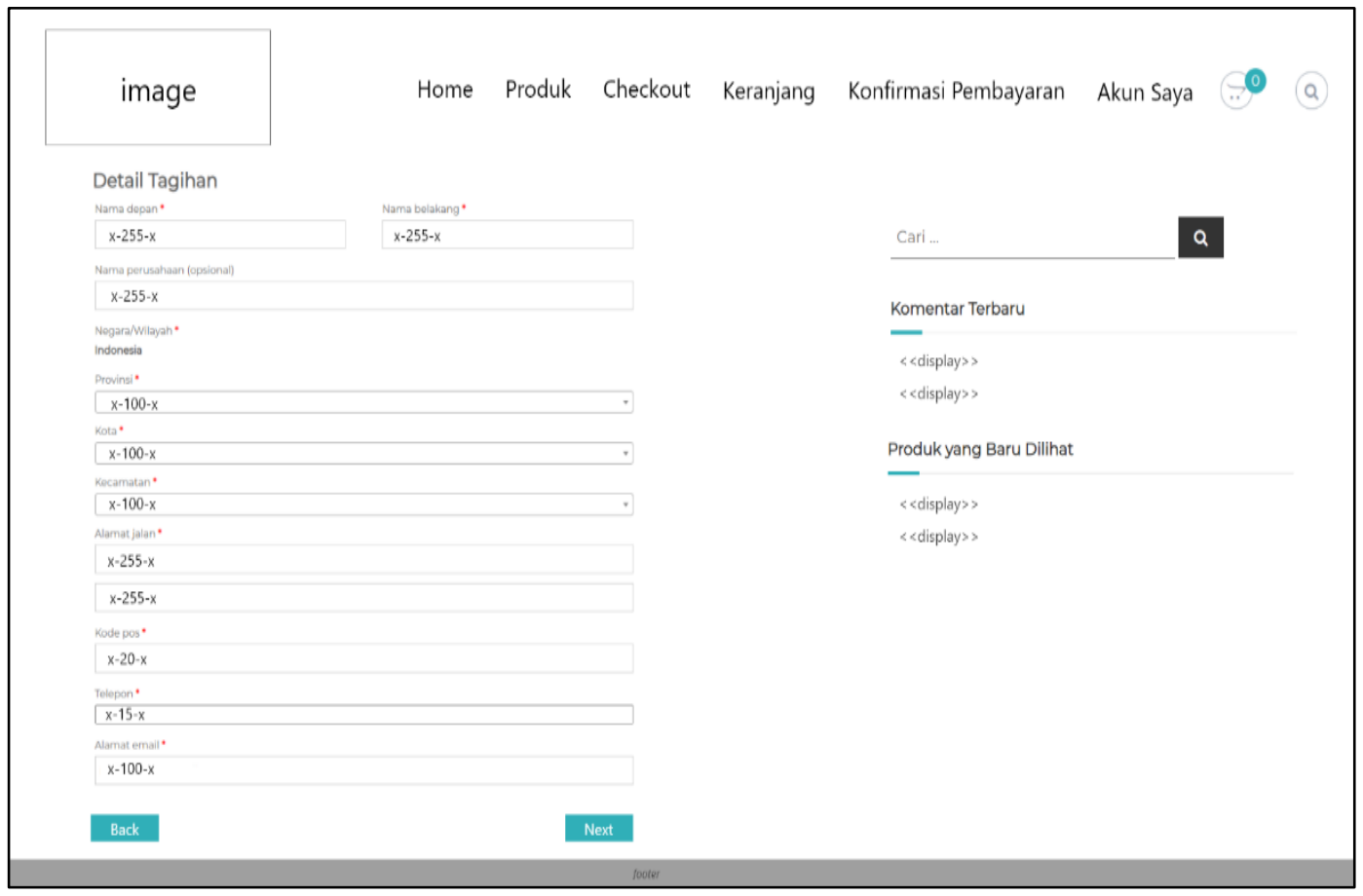

Gambar 7. Rancangan Layar Checkout 


\section{Halaman 9-18}

available online at http://jom.fti.budiluhur.ac.id/index.php/IDEALIS/index

c. Rancangan Layar Konfirmasi Pembayaran

Layar ini digunakan oleh pembeli untuk melakukan konfirmasi pembayaran pada website Toko Arleuis dengan meng-upload bukti pembayaran, halaman ini seperti terlihat pada Gambar 8. Rancangan Layar Konfirmasi Pembayaran.

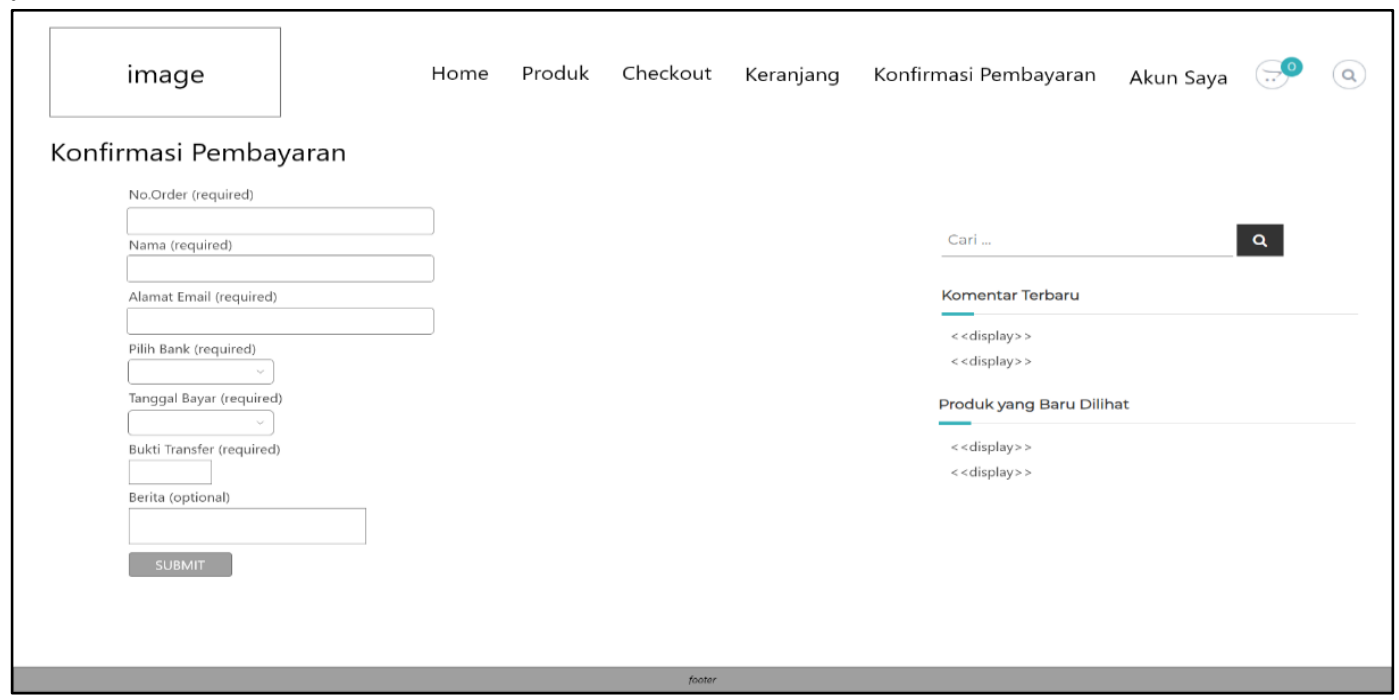

Gambar 8. Rancangan Layar Konfirmasi Pembayaran

d. Rancangan Layar Pengembalian Barang

Rancangan layar pengembalian barang ini digunakan untuk pembeli jika ingin melakukan pengembalian barang, rancangan layar input pengembalian barang ini seperti terlihat pada Gambar 9. Rancangan Layar Pengembalian Barang.

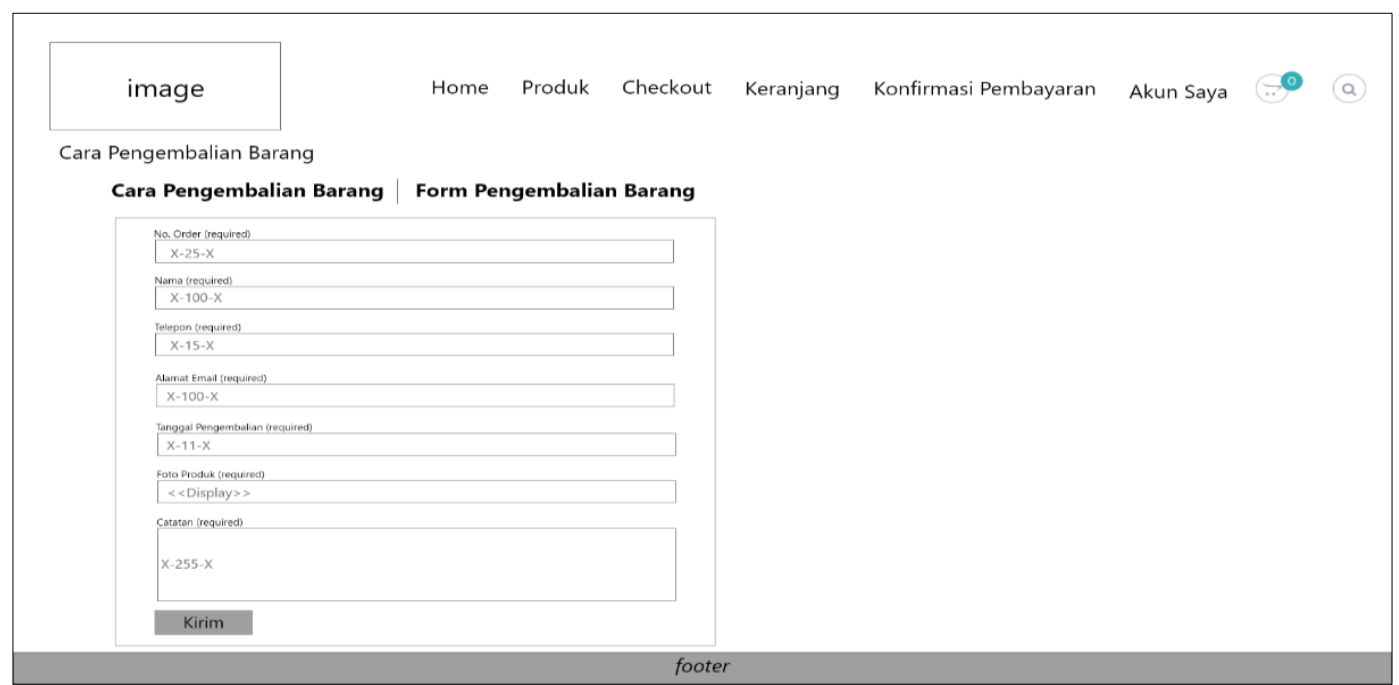

Gambar 9. Rancangan Layar Pengembalian Barang

\subsection{Strategi Search Engine Optimization (SEO)}

SEO merupakan teknik memaksimalkan halaman web untuk membuatnya dikenal atau dibaca oleh mesin pencari. Perujukan teknis SEO dijalankan melalui proses sistematis. Dalam arti, teknik SEO wajib mengikuti aturan yang diterapkan pada mesin pencari tertentu dengan sebuah referensi. [9]. Berikut ini dijelaskan langkah yang digunakan oleh penulis dalam melakukan optimasi SEO pada website Toko Arleuis : 
a. Pengoptimasian Halaman Produk

Pada halaman Produk ini selain mengisi detail dari produk yang nantinya akan ditampilkan pada halaman website Toko Arleuis admin juga diharuskan melengkapi kolom yang terdapat pada Yoast SEO yang diantaranya ada Frasa kunci utama, Judul SEO, Slug, dan Deskripsi Meta. Seperti yang ditampilkan pada Gambar 10. Pengoptimasian Halaman Produk.

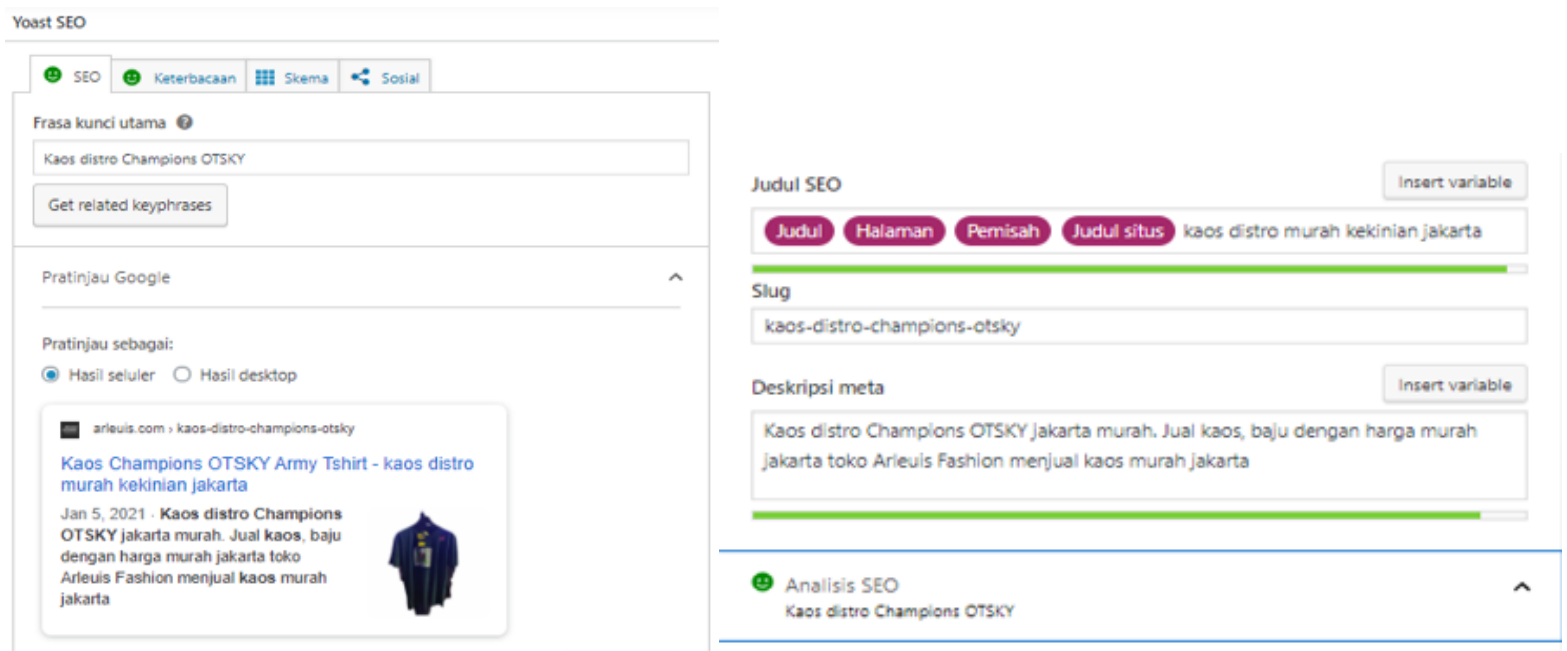

b. Hasil Optimasi Halaman Produk

Gambar 10. Pengoptimasian Halaman Produk

Setelah semua tahapan pada strategi optimasi SEO dilakukan maka hasil dari optimasi SEO tersebut dapat di lihat pada Gambar 11. Hasil Optimasi Halaman Produk. Pengambilan gambar dari hasil optimasi SEO ini dilakukan pada 14 Januari 2021, pukul 16.00 WIB dengan kata kunci pencarian pada Search Engine Google "kaos champions otsky jakarta".

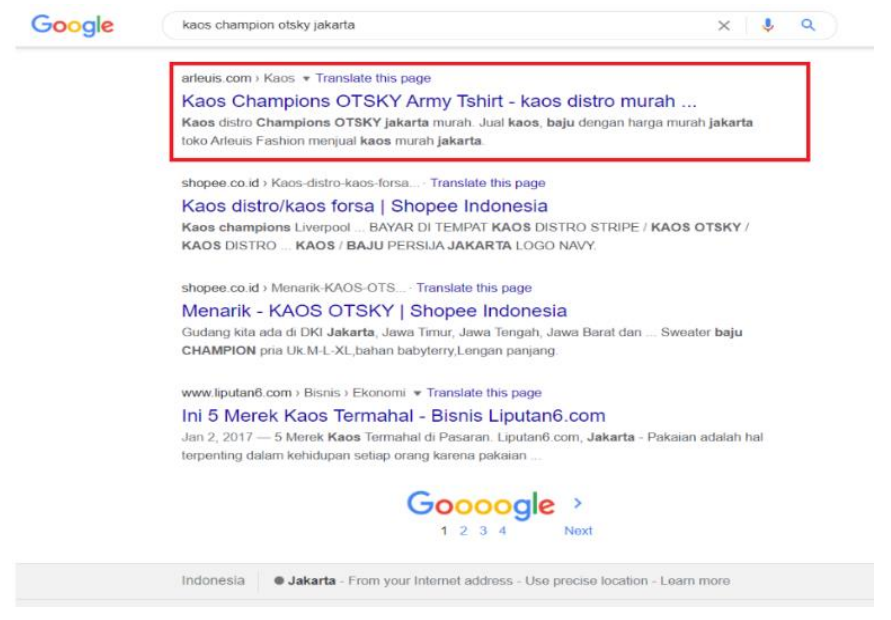

Gambar 11. Hasil Optimasi Halaman Produk

\subsection{Strategi Pemasaran}

Strategi pemasaran adalah upaya perusahaan untuk menganalisis segmentasi pasar yaitu merupakan kelompok orang yang menjadi target pemasaran, dan melakukan penciptaan bauran pemasaran yang tepat untuk memenuhi kebutuhan pasar yang sesuai. Keberhasilan strategi pemasaran dipengaruhi oleh beberapa alat pemasaran yang lebih dikenal sebagai marketing mix yang terdiri dari Price, Product, Promotion, dan Place. Pada pelaksanaannya alat pemasaran tersebut dilakukan dengan cara lain yang unik, dengan tujuan akhirnya adalah meningkatkan penjualan dan memperoleh keuntungan dari produk yang diproduksi perusahaan atau instansi terkait [10]. Strategi Pemasaran yang diterapkan pada toko Arleuis adalah sebagai berikut : 
a. Up Selling

Dengan mengadakan potongan harga pada beberapa produk yang ada pada website, teknik ini akan mendorong pembeli membelanjakan uangnya lebih banyak lagi, di karenakan pembeli akan tertarik dengan strategi pemotongan harga seperti diskon produk dan promo pada hari - hari perayaan dan libur nasional.

b. Membuat Sosial Media Instagram

Pada zaman seperti saat ini tidak bisa dipungkiri lagi kecepatan melakukan iklan produk di sosial media akan sangat cepat dan efektif. Contohnya dengan memasarkan produk lewat Instagram, adapun Instagram dari Toko Arleuis instagram.com/arleuis_merch.

\section{KESIMPULAN}

Kesimpulan dari Implementasi E-Commerce Dengan Menggunakan CMS (Content Management System) Dan BMC (Business Model Canvas) Pada Toko Pakaian Arleuis yaitu dengan adanya website e-commerce ini para pembeli yang ingin berbelanja produk Toko Arleuis bisa langsung mengunjungi website Toko Arleuis (https://arleuis.com) selain itu diharapkan juga dengan adanya website e-commerce ini dapat semakin memperluas jangkauan pasar dari Toko Arleuis dan meningkatkan loyalitas pembeli karna kemudahan akses pembelian yang bisa dilakukan dimana saja dan kapan saja, selain itu untuk para pegawai dan pemilik Toko bisa dengan mudah melakukan pengontrolan stok dan memberikan informasi terkait stok produk kepada pelanggan dengan mudah. Oleh karena itu masalah pelanggan yang sering kehabisan stok bisa teratasi karna informasi mengenai stok produk selalu diperbarui.

\section{DAFTAR PUSTAKA}

[1] Y. Aryasuta and B. Cahya Putra, "Penerapan Business Model Canvas Untuk Meningkatkan Penjualan Peralatan Beladiri Pada Toko Danis," Jurnal IDEALIS, vol. 3, no. 1, pp. 49-55, 2020.

[2] D. Ananda and I. Novita, "Sistem Informasi Penjualan Berbasis E-Commerce Untuk Mengoptimalkan Penjualan Batik Pada Toko Al-Barokah Batik," Jurnal IDEALIS, vol. 3, no. 2, pp. 28-32. 2020.

[3] D. Renca and H. Hasugian, "Pembuatan Website Berbasis E-Commerce Menggunakan Business Model Canvas Pada Toko Brassica Florist,” Jurnal IDEALIS, vol. 2, no. 6, pp. 258-264, 2019.

[4] R. Ramadhan and I. Novita, "Perancangan E-Commerce Untuk Meningkatkan Penjualan Pada Space Vapor Store," Jurnal IDEALIS, vol. 3, no. 1, pp. 152-156, 2020.

[5] M. R. Haiqal and Y. Yuliazmi, "Perancangan E-Commerce Pada Jeys Corner Untuk Meningkatkan Penjualan Menggunakan Metode Business Model Canvas," Jurnal IDEALIS, vol. 3, no. 2, pp. 9-14, 2020.

[6] A. Fadillah and L. Fajarita, "Perancangan dan pembangunan aplikasi e-commerce berbasis web untuk meningkatkan penjualan pada toko jaket kulit naufal," Jurnal IDEALIS, vol. 3, no. 1, pp. 85-91, 2020.

[7] M. Tabrani and I. Aghniya, "Implementasi Metode Waterfall Pada Program Simpan Pinjam Koperasi Subur Jaya Mandiri Subang,” Jurnal Interkom, vol. 14, no. 1, pp. 44-53, 2019.

[8] E. Revsie Akbar and H. Irawan, “Analisis dan Implementasi E-Commerce Menggunakan CMS Wordpress Pada Queenita Classic,” Jurnal IDEALIS, vol. 4, no. 1, pp. 107-116, 2021.

[9] A. Sofyan, E. Ferdianto, R. Rahmawati, and R. K. Aldi, "Pengaruh Search Engine Optimization (SEO) Dan Riset Kata Kunci Terhadap Pendapatan Toko Online," Indonusa Conf. Technol. Soc. Sci., vol. 1, no. 1, pp. 351-356, 2019.

[10] E. Wawolumaya, D. Tampi, and J. Rogahang, “Analisis Strategi Pemasaran Dalam Upaya Meningkatkan Volume Penjualan Pada Rose Collection Manado,”Ejournal UNNSRAT, vol. 1, no. 2, pp. 134-141, 2020. 